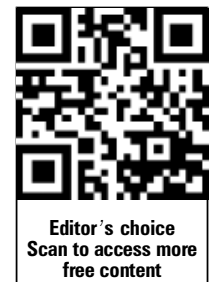

${ }^{1}$ Rheumatology Unit, Danderyd's Hospital, Karolinska Institutet, Stockholm, Sweden

${ }^{2}$ Unit of Cardiovascular Epidemiology, Institute of Environmental Medicine, Karolinska Institutet, Stockholm, Sweden ${ }^{3}$ Neuroimmunology, Department of Clinical Neurosciences, Karolinska Institutet, Stockholm, Sweden ${ }^{4}$ Department of Translational Research, Kennedy Institute London, UK

${ }^{5}$ Rheumatology Unit Department of Medicine Karolinska University Hospital, Solna, Karolinska Institutet, Stockholm, Sweden

Correspondence to Dr Payam Azali, Rheumatology Unit, Danderyd's Hospital, Karolinska Institutet, Stockholm 18288, Sweden; payam.azali@ds.se

$\mathrm{PA}$ and $\mathrm{SBH}$ contributed equally

Accepted 21 August 2012 Published Online First 19 September 2012

\section{SLinked}

- http://dx.doi.org/10.1136/ annrheumdis-2012-202538

- http://dx.doi.org/10.1136/ annrheumdis-2012-202302

\title{
Low serum levels of vitamin D in idiopathic inflammatory myopathies
}

\author{
Payam Azali, ${ }^{1}$ Sevim Barbasso Helmers, ${ }^{2}$ Ingrid Kockum, ${ }^{3}$ Tomas Olsson, ${ }^{3}$ \\ Lars Alfredsson, ${ }^{2}$ Peter J Charles, ${ }^{4}$ Karin Piehl Aulin, ${ }^{1}$ Ingrid E Lundberg ${ }^{5}$
}

\section{ABSTRACT}

Objectives To evaluate serum levels of $25(\mathrm{OH})$ vitamin $\mathrm{D}$ in patients with idiopathic inflammatory myopathies (IIM) (polymyositis (PM), dermatomyosistis (DM), inclusion body myositis (BBM) and juvenile DM (JDM)) and to compare these with healthy controls.

Methods Serum samples from 149 patients with IIM and 290 healthy controls matched for gender and the month of blood sampling were analysed for $25(\mathrm{OH})$ vitamin D. ORs for vitamin D classes with $95 \% \mathrm{Cl}$ were calculated using a matched (conditional) logistic regression model. Groups were compared by the Kruskal-Wallis test and $p$ values $<0.05$ were considered significant.

Results Patients with IIM had significantly lower serum levels of $25(\mathrm{OH})$ vitamin $D$ than healthy controls (median $39(10-168) \mathrm{nmol} / \mathrm{l}$ vs 68 (19-197) nmol/; $p=0.0001)$. There was no significant difference in vitamin $D$ levels between the myositis subgroups. When vitamin $\mathrm{D}$ levels were subclassified into deficient $(<50 \mathrm{nmol} / /)$, insufficient $(50-74 \mathrm{nmol} / \mathrm{l})$ and normal $(\geq 75 \mathrm{nmol} / \mathrm{l})$, most of the patients with PM (68\%), DM $(65 \%)$ and IBM $(53 \%)$ had deficient levels compared with only $60(21 \%)$ healthy individuals. In patients with IIM the OR for deficient versus normal was 17.7 (95\% Cl 8.1 to 38.6$)$ and the OR for insufficient versus normal was 2.4 (95\% Cl 1.2 to 4.7$)$.

Conclusions Low serum levels of vitamin $\mathrm{D}$ were found in most patients with IIM and may confer a risk factor for developing adult myositis, similar to some other autoimmune diseases.

\section{INTRODUCTION}

Idiopathic inflammatory myopathies (IIM) are chronic inflammatory disorders characterised clinically by symmetrical progressive muscle weakness and histologically by inflammatory cell infiltrates in muscle tissue. Based on different clinical and histopathological features, IIM can be classified into three major subgroups: polymyositis (PM), dermatomyosistis (DM) and inclusion body myositis (IBM). ${ }^{1}{ }^{2}$ The inflammatory infiltrates in muscle tissue are predominantly composed of $\mathrm{T}$ lymphocytes, macrophages, dendritic cells and B lymphocytes. ${ }^{3}$ Other organ manifestations are often present such as skin rash in DM or interstitial lung disease in both PM and DM. Autoantibodies are frequently detected in PM and DM (up to $80 \%$ ), ${ }^{4}$ but less often in patients with IBM $(20 \%) .{ }^{5}$ Some autoantibodies are myositisspecific, of which the anti-histidyl tRNA synthetase (anti-Jo-1) is the most common and can be found in all subsets of IIM. ${ }^{6}$ Based on the observations of immune cells in muscle tissue and the frequent presence of autoantibodies, PM and DM are considered autoimmune disorders whereas, for IBM, the role of the immune system in the pathogenesis is more debatable. ${ }^{78}$ Both genetic and environmental factors are likely to contribute to the aetiology of IIM, although their relative contribution to disease susceptibility has not been clarified. ${ }^{9-12}$ In DM, ultraviolet (UV) light is one suggested risk factor. ${ }^{13} 14$ There are also seasonal variations for the onset of PM and DM, with the onset of anti-Jo-1 positive myositis seeming to occur preferentially in the spring whereas the anti-Mi-2 positive $\mathrm{DM}$ has a peak of onset during the summer months. ${ }^{13} 15$

In the context of autoimmunity, vitamin $\mathrm{D}$ is an interesting factor as low levels of vitamin $\mathrm{D}$ have been associated with several autoimmune diseases including type 1 diabetes mellitus, multiple sclerosis (MS), inflammatory bowel disease, systemic lupus erythematosus (SLE) and rheumatoid arthritis (RA). ${ }^{16-19}$ 1,25-dihydroxy vitamin $\mathrm{D}$, the final active metabolite of vitamin $\mathrm{D}$, is converted by 7-dehydrocholesterol upon UV-B radiation. As a member of the class II steroid hormones, it exerts immune regulating, mainly suppressive properties, acting through vitamin $\mathrm{D}$ receptor. ${ }^{20} 1,25$-dihydroxy vitamin $\mathrm{D}$ inhibits T lymphocyte proliferation, ${ }^{21} 22$ particularly $\mathrm{Th} 1,{ }^{23}$ inhibits cytokine secretion such as interleukin 2 (IL-2) and interferon $\gamma$ (IFN $\gamma$ ) by CD4 $\mathrm{T}$ lymphocytes and suppresses antibody secretion and autoantibody production from B lymphocytes. ${ }^{24}$ Antigen presenting cells such as dendritic cells and macrophages are also affected by 1,25-dihydroxy vitamin $\mathrm{D}$. It is one of the most powerful blockers of dendritic cell differentiation and IL-12 secretion in vitro. ${ }^{25} 26$ In addition, vitamin D may induce monocyte differentiation into macrophages and modulate the macrophage response such as release of inflammatory cytokines and chemokines. ${ }^{27}$

In this study we aimed to investigate whether low levels of vitamin $\mathrm{D}$ could be a risk factor for patients with IIM living in a northern country with seasonal variations of UV light exposure and vitamin D levels. We compared serum levels of vitamin D between patients with IIM and healthy controls. As serum levels of vitamin $\mathrm{D}$ vary with the season, we also matched for month of serum sampling. Furthermore, we wanted to investigate whether there was a difference between the IIM subclasses DM, PM, IBM and juvenile onset DM (JDM) as well as between patients with or 
without autoantibodies. Moreover, we wanted to investigate if the vitamin $\mathrm{D}$ levels differed between patients in early disease and those with established disease.

\section{METHODS}

\section{Subjects}

This was a cross-sectional retrospective observational casecontrol study. All cases were identified from the myositis register at the Rheumatology Unit, Karolinska University Hospital, Solna, Stockholm. A total of 169 patients fulfilled the criteria for definitive, probable or possible PM, DM or JDM according to Bohan and Peter $^{28}$ or criteria for IBM. ${ }^{2}$ From 149 of these cases, non-thawed frozen serum samples were available and were included in this study. Seventy-six patients (51\%) were classified as PM, 52 (35\%) as DM, 6 (4\%) as JDM and 15 (10\%) as IBM. Patient characteristics are presented in table 1. For the cases we aimed to analyse the blood sample which was taken at the time of diagnosis. For patients with a long disease duration, blood samples from the time of diagnosis were not always available $(n=95)$. In these cases the serum sample that was available closest to the diagnosis date was selected for the analysis. For one case there was no information on date of diagnosis. Sixty-six cases (44\%) had a disease duration $\leq 3$ months from diagnosis at blood sampling and were considered as early cases and 83 (56\%) had a disease duration >3 months and were considered as having established disease. The serum samples had been stored frozen at $-80^{\circ} \mathrm{C}$.

Table 1 Demographic data and clinical characteristics of cases and controls

\begin{tabular}{|c|c|c|c|}
\hline & Cases & & Controls \\
\hline Gender, n (\%) & 149 & & 290 \\
\hline Male & $52(35)$ & & $98(34)$ \\
\hline Female & $97(65)$ & & $192(66)$ \\
\hline \multicolumn{4}{|l|}{ Age, year (at blood sampling) } \\
\hline Median (range) & $56(18-72)$ & & $41(18-70)$ \\
\hline Disease duration, ${ }^{*}$ (months) & & & - \\
\hline Median (range) & $6.5(0-368)$ & & \\
\hline Disease duration, ${ }^{*} \mathrm{n}(\%)$ & & & - \\
\hline$\leq 3 \mathrm{~m}$ & $66(44)$ & & \\
\hline$>3 \mathrm{~m}$ & $83(56)$ & & \\
\hline Subdiagnosis, n (\%) & & & - \\
\hline PM & $76(51)$ & & \\
\hline DM & $52(35)$ & & \\
\hline IBM & $15(10)$ & & \\
\hline JDM & $6(4)$ & & \\
\hline \multicolumn{4}{|l|}{ Autoantibodies } \\
\hline Anti-Jo-1, n (\%) & $23(16)$ & $145 \dagger$ & - \\
\hline Other AsAb $\ddagger$, $(\%)$ & $3(2)$ & $130 t$ & - \\
\hline Anti-SSA§, n (\%) & $44(34)$ & $130 t$ & - \\
\hline Anti-SSB, n (\%) & $7(6)$ & $128 t$ & - \\
\hline Anti-Mi-2, n (\%) & $3(7)$ & $43 \dagger$ & - \\
\hline Anti-SRP, n (\%) & $5(6)$ & $84 \dagger$ & - \\
\hline
\end{tabular}

*Disease duration calculated from diagnosis to date of blood sampling. tTotal number of cases with available results from antibody analysis. fanti-PL-7, anti-PL-12, anti-EJ, anti-0J, anti-KS, anti-ZO.

$\S S S A / R 052$ and/or SSA/Ro60: six patients had an overlap syndrome (rheumatoid arthritis in 1, systemic sclerosis in 2, Sjögren's syndrome in 2, mixed connective tissue disease in 1).

AsAb, anti-synthetase antibody; DM, dermatomyositis; IBM, inclusion body myositis; JDM, juvenile dermatomyositis; PM, polymyositis; SSA, Sjögren's syndrome antigen $A, S S B$, Sjögren's syndrome antigen $B$; SRP, signal recognition particle.
The controls were selected from a population-based randomly drawn control group that had been identified as controls for the Epidemiological Investigation of Multiple Sclerosis, a Swedish case-control study for MS. ${ }^{16} 29$ The controls had been identified through a national population registry and encompassed 1194 Swedish controls with Scandinavian ancestry. They had received a kit through the mail that contained sample tubes and a referral letter to a laboratory where the blood was drawn. For each IIM case, two gender-matched controls were selected where possible. The controls were also matched for the month of blood sampling (only men born in November got one control each). Two hundred and ninety controls were included in the study (table 1).

The study was approved by the regional ethics committee of Karolinska University Hospital, Stockholm, Sweden and patients and controls gave their consent for the study.

\section{Vitamin D levels}

Serum/plasma samples from the cases and controls were analysed for $25(\mathrm{OH})$ vitamin $\mathrm{D}$ at the same laboratory, Clinical Chemistry Laboratory, Karolinska University Hospital Solna, Stockholm, Sweden (LIAISON 25OH Vitamin D TOTAL analysis, DiaSorin Inc, Stillwater, Minnesota, USA), which uses the chemiluminescence immunoassay technique for quantification of $25(\mathrm{OH})$ vitamin $\mathrm{D}$. The concentration is expressed as $\mathrm{ng} / \mathrm{ml}$ and the result can be transformed to SI units using the formula: $\mathrm{ng} / \mathrm{ml} \times 2.5=\mathrm{nmol} / \mathrm{l}$. The reference range for vitamin $\mathrm{D}$ levels was $75-250 \mathrm{nmol} / 1$.

\section{Clinical and laboratory data}

Clinical data were retrieved from medical records and from a myositis register at the Rheumatology Unit, Karolinska University Hospital. For 135 patients, autoantibody profiles for myositis-specific and myositis-associated autoantibodies were analysed by line blot assay (Euroimmune AG, Lübeck, Germany) at the Kennedy Institute, London. For the remaining 14 patients the Multiplex Antinuclear Antibody Assay (BioPlex 2200 System, Bio-Rad Inc Laboratories, Hercules, CA, USA) was used, tested as clinical routine at the Department of Clinical Immunology, Karolinska University Hospital.

\section{Statistical analyses}

GraphPad Prism 4.0 statistical software (GraphPad, San Diego, California, USA) was used for the following tests. Vitamin D levels were compared by the Kruskal-Wallis test between multiple groups. The Mann-Whitney $U$ test was used to compare vitamin $\mathrm{D}$ levels between the two groups. The Spearman rank correlation coefficient was used to test for correlations. $p$ Values $\leq 0.05$ were considered significant. ORs for vitamin D classes with $95 \%$ CI were calculated by means of a matched (conditional) logistic regression model. The SAS software package V.9.2 (SAS Institute, Cary, North Carolina, USA) was used to calculate ORs and $95 \% \mathrm{CI}$.

\section{RESULTS}

Patients with IIM had significantly lower serum levels of $25(\mathrm{OH})$ vitamin $\mathrm{D}$ than healthy controls (median 38.5 (range 10-168) $\mathrm{nmol} / \mathrm{l}$ vs 68.0 (range 19-197) nmol/l, $\mathrm{p}=0.0001$; figure $1 \mathrm{~A}$ ).

In the IIM subgroups the median (range) vitamin $\mathrm{D}$ levels were 35.5 (10-168) nmol/1 for PM, 43.9 (14-133) nmol/1 for DM, 45.0 (11-84) nmol/1 for IBM and 53.0 (18-78) nmol/l for JDM. There was no significant difference in vitamin $\mathrm{D}$ levels between the myositis subgroups. There was no difference in the vitamin $\mathrm{D}$ levels between men and women in the IIM group but, in the control group, men had lower levels than women. 
A

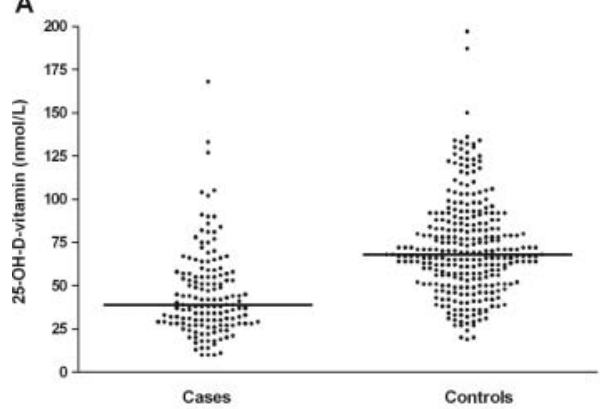

C

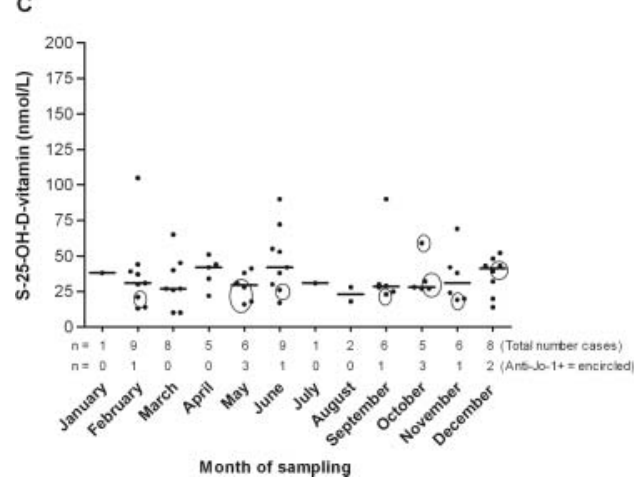

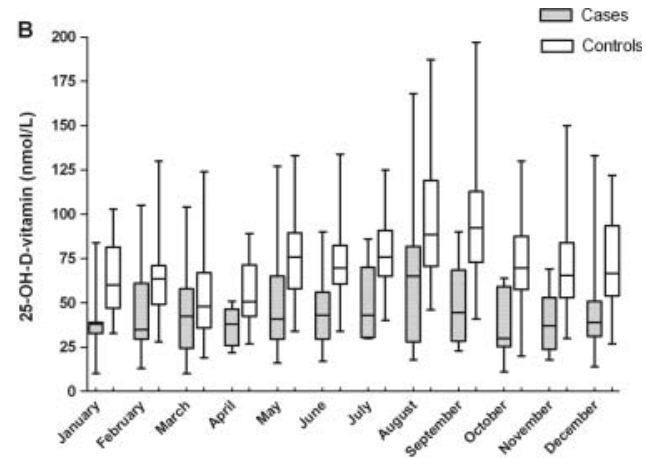

Month of sampling

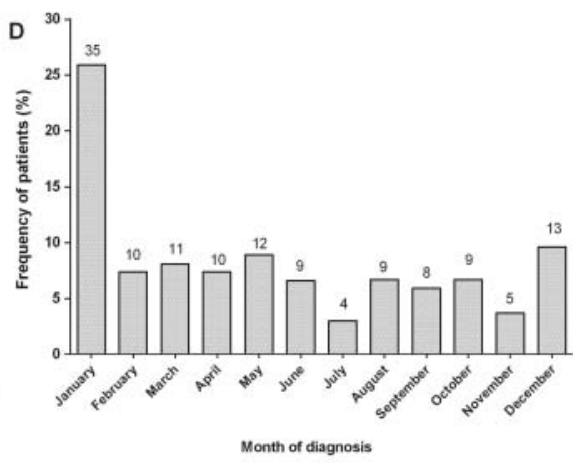

Figure 1 (A) Patients with idiopathic inflammatory myopathies (IIM) had significantly lower serum levels of vitamin D than healthy individuals $(p=0.0001)$. (B) Median levels of monthly variations of vitamin D levels in patients with IIM and healthy controls. (C) Median levels of monthly variations of vitamin D levels in patients with IIM positive for anti-Jo-1 autoantibodies and with disease duration $\leq 3$ months. (D) Month of diagnosis of patients with IIM.

The vitamin $\mathrm{D}$ levels were subclassified into three categories: deficient $(<50 \mathrm{nmol} / \mathrm{l})$, insufficient $(50-74 \mathrm{nmol} / \mathrm{l})$ and normal ( $\geq 75 \mathrm{nmol} / \mathrm{l})$. Most of the patients with PM (69\%), DM (65\%) and IBM (53\%) had deficient levels while most of the populationbased controls had normal or insufficient vitamin D levels (table 2). There were significant differences in vitamin $\mathrm{D}$ levels when the PM, DM and IBM subgroups were compared with the controls $(p<0.001)$. The difference in vitamin $D$ levels between JDM cases and controls was not significant. The ORs for the different subclasses of vitamin D levels in the whole IIM cohort were 17.7 (95\% CI 8.1 to 38.6) for deficient versus normal and 2.4 (95\% CI 1.2 to 4.7$)$ for insufficient versus normal. After adjustment for age, the ORs changed to 13.6 (95\% CI 5.8 to 31.7 ) for

Table 2 Number (\%) of cases and controls with deficient, insufficient or normal serum levels of vitamin D

\begin{tabular}{lllcl}
\hline & $\begin{array}{l}\text { Deficient } \\
(<\mathbf{5 0} \mathbf{~ n o l} / \mathbf{l})\end{array}$ & $\begin{array}{l}\text { Insufficient } \\
(\mathbf{5 0 - 7 4} \mathbf{~ m o l} / \mathbf{l})\end{array}$ & $\begin{array}{l}\text { Normal } \\
(\geq \mathbf{7 5} \mathbf{~ m o l} / \mathbf{l})\end{array}$ & Total \\
\hline Controls & $60(21)$ & $113(39)$ & $117(40)$ & $290(100)$ \\
Cases & $96(64)$ & $35(24)$ & $18(12)$ & $149(100)$ \\
PM & $52(69)$ & $14(18)$ & $10(13)$ & $76(51)$ \\
DM & $34(65)$ & $12(23)$ & $6(12)$ & $52(35)$ \\
IBM & $8(53)$ & $6(40)$ & $1(7)$ & $15(10)$ \\
JDM & $2(33)$ & $3(50)$ & $1(17)$ & $6(4)$ \\
Anti-Jo-1+* & $14(61)$ & $6(26)$ & $3(13)$ & $23(16)$ \\
\hline
\end{tabular}

*Anti-Jo-1 autoantibody analysis was available for 145 cases. DM, dermatomyositis; IBM, inclusion body myositis; JDM, juvenile dermatomyositis; PM, polymyositis. deficient versus normal and 2.1 (95\% CI 1.0 to 4.4) for insufficient versus normal. No correlation was observed between age at sampling and vitamin $D$ levels for cases $(p=0.37)$ or for controls $(p=0.56)$.

Anti-Jo-1 autoantibody analysis was available for 145 cases, 23 of whom (16\%) were positive for anti-Jo-1 autoantibodies. Most of the anti-Jo-1 positive patients (61\%) were in the group with deficient levels of vitamin $\mathrm{D}$, the second largest group of patients was in the category with insufficient vitamin $\mathrm{D}$ levels and the lowest number of patients was in the normal category of vitamin $\mathrm{D}$ levels (table 2). Patients with anti-Jo-1 autoantibodies had significantly lower median vitamin $\mathrm{D}$ levels than controls (38.0 (range 10-168) nmol/l vs 68.0 (range 19-197) nmol/1, p<0.0001). When the median levels of vitamin $\mathrm{D}$ in all autoantibody positive patients (40.0 (range 10-168) nmol/l) were compared with those in all autoantibody negative patients (38.0 (range 11-104) nmol/l), no significant difference was seen.

There was also a difference in vitamin $\mathrm{D}$ levels with disease duration, with lower levels in patients with disease duration $\leq 3$ months than in those with disease duration $>3$ months (table 3 ). There was a positive correlation between disease duration in months and vitamin D levels $(r=0.300, p=0.0001)$.

Finally, we analysed levels of vitamin $\mathrm{D}$ during the different months of serum sampling. As expected, the vitamin D levels varied over the year, being lowest in the winter and spring months. The pattern of seasonal variation was different between cases and controls in this respect (figure 1B,C). When assessing the month of diagnosis of the patients, the highest frequency of myositis diagnosis was made during January, which is during the period of seasonal low vitamin $D$ levels (figure 1B,D). 
Table 3 Median serum levels of vitamin $D(\mathrm{nmol} / \mathrm{l})$ in patients with disease duration $\leq 3$ months and $>3$ months

\begin{tabular}{llll}
\hline & \multicolumn{2}{l}{ Disease duration* } & \\
\cline { 2 - 3 } & $\leq \mathbf{3}$ months & $>\mathbf{3}$ months & p Value \\
\hline Cases (n) & 66 & 83 & $<0.0001$ \\
Median (range) & $31(10-105)$ & $50(10-168)$ & $<0.0001$ \\
Mean \pm SD & $36 \pm 19$ & $53 \pm 27$ & $<0.0001$ \\
Coefficient of variation & $52.07 \%$ & $51.44 \%$ & \\
\hline
\end{tabular}

*Disease duration calculated from the diagnosis to date of blood sampling.

\section{DISCUSSION}

We found that adult patients with IIM of all subclasses (PM, DM and IBM) have significantly lower serum levels of vitamin D compared with gender-matched population based control samples collected during the same month of the year. Furthermore, the vitamin D levels were lower in samples taken close to diagnosis than in samples taken during established disease, which suggests that low levels of vitamin D may be a risk factor for developing adult IIM. To the previously reported autoimmune diseases such as MS, RA and SLE ${ }^{17} 1830$ where vitamin $\mathrm{D}$ seems to be a risk factor, we can now add adult PM, DM and IBM.

The OR for vitamin $\mathrm{D}$ deficiency was high for IIM patients, even higher than that seen in MS cases in Sweden. ${ }^{31}$ There was also a significant difference between each of the PM, DM and IBM subgroups compared with controls when we focused on the vitamin D deficiency subclass. Vitamin D levels can be considered as a proxy for sun exposure. In northern latitudes, solar radiation is not sufficient for the synthesis of enough vitamin $\mathrm{D}$ for almost half of the year (autumn-winter season) leading to a risk of vitamin $\mathrm{D}$ deficiency. As a result there is a strong seasonal variation in circulating levels of $25(\mathrm{OH})$ vitamin $\mathrm{D}$ in these countries. ${ }^{32}$ Such seasonal variations in the vitamin $\mathrm{D}$ level were also seen in our study, but with unexpected differences between cases and controls. Cases had peak vitamin D levels in August followed by a depression in October (figure 1B) whereas controls had a depression in March and then increasing levels to the end of the spring and during the summer (figure 1B). One possible explanation could be that the vitamin D metabolism in the responsible body organs (from the gastrointestinal tract to the skin and liver) may vary between patients with IIM who have inflammation in several organs and healthy individuals. Notably, the vitamin D levels in the adult IIM cases were significantly lower than the serum levels of controls even when the same month of blood sampling was compared. This was also seen in adult cases with DM where UV light exposure is a previously reported risk factor. ${ }^{11}{ }^{33}$ This has particularly been related to the DM subgroup with anti Mi-2 autoantibodies. Notably, these autoantibodies were rarely found among our patients with $\mathrm{DM}$, suggesting that there may be different risk factors for various subsets of DM and that vitamin D deficiency may constitute a risk factor for some patients with DM as well as for PM and IBM. Similar seasonal changes in vitamin D levels have been observed for patients with RA and SLE where the vitamin D levels also correlated inversely with disease activity. ${ }^{34} 35$ In concordance with RA onset, the IIM cases were diagnosed more frequently during winter or spring (figure 1D). ${ }^{36}$

Strikingly, most of the anti-Jo-1 positive patients were in the group with deficient vitamin $\mathrm{D}$ levels (table 2). Recently, low vitamin $\mathrm{D}$ levels have been associated with ANA positivity in healthy controls and with anti-dsDNA titre in SLE, suggesting a role for vitamin $\mathrm{D}$ in autoantibody formation. ${ }^{37}{ }^{38}$ Patients with SLE with vitamin D deficiency had higher IFN $\alpha$ and B cell activity than patients without vitamin D deficiency. Notably, patients with anti-Jo-1 positivity were associated with type I IFN activity and high serum levels of B cell activating factor, which might indicate a role for vitamin D deficiency in autoantibody production in these patients. ${ }^{39}{ }^{40}$ In patients with JDM, higher IFNa levels were seen with shorter disease duration but information on vitamin $\mathrm{D}$ levels was not included in this report. ${ }^{41}$ Measurement of interferon activity was beyond the scope of our study and the number of JDM cases was too low to allow any conclusions. The role of autoimmunity in patients with IBM is controversial, although a subgroup of patients with IBM had features of other autoimmune diseases and autoantibodies. ${ }^{5}{ }^{42}$ In our rheumatology setting we cannot exclude a bias towards this subset.

We observed that vitamin D levels correlated positively with disease duration ( $\leq 3$ months). One explanation for the low levels of vitamin $\mathrm{D}$ in the early phase of disease might be disability and difficulties in being outdoors because of musculoskeletal symptoms. This may be particularly relevant for patients with IBM who often have a very slowly progressive muscle weakness and a long delay before being diagnosed, but this could not be answered by our study. The higher serum levels of vitamin $\mathrm{D}$ in patients with established disease than in those with early disease could possibly be explained by the administration of a calcium vitamin D supplement together with glucocorticoid treatment as prophylaxis against osteoporosis. However, the vitamin $\mathrm{D}$ dosage given as a supplement with calcium is lower than the recommended dose for treatment of vitamin D deficiency, so the supplement is not likely to explain the higher levels during established disease. Details of the use of a vitamin D supplement were missing in many patients which prevented us from calculating achieved doses.

Interestingly, vitamin D supplements could be therapeutically effective in autoimmune diseases, as demonstrated in some studies with animal models-for example, in mice with experimental autoimmune encephalomyelitis, ${ }^{43}{ }^{44}$ collagen-induced arthritis, ${ }^{45}$ type 1 diabetes mellitus ${ }^{46}$ or autoimmune thyroiditis. ${ }^{47}$ In patients with MS, a vitamin D supplement has been suggested as part of the management ${ }^{48}$ but the documentation on therapeutic intervention with vitamin D in already established MS is limited. Whether the therapeutic effectiveness of vitamin $\mathrm{D}$ is true in other autoimmune diseases is not known.

Our study has limitations. First, the controls were generally younger than the cases but this is not likely to explain the differences between patients and controls as no correlation between age and vitamin $\mathrm{D}$ levels was found among the controls and the significant difference between patients and controls persisted after adjustment for age. Another general limitation is that the low vitamin $\mathrm{D}$ levels may be a consequence of the disease rather than a cause, and at least some of the cases may have taken vitamin $\mathrm{D}$ supplements for different lengths of time before blood sampling, particularly after IIM diagnosis, with glucocorticoid treatment. To overcome this problem, we divided the cases into two groups with disease duration shorter or longer than 3 months. Indeed, the patients with shorter disease duration had lower levels of vitamin $\mathrm{D}$ than those with established treated disease. This supports our hypothesis that low levels of vitamin $\mathrm{D}$ could be one of several risk factors for the development of IIM.

In summary, low serum levels of vitamin $\mathrm{D}$ were found in most adult patients with IIM. The deficient vitamin D levels in patients with disease of shorter duration ( $<3$ months) and the 
seasonality of the disease support the role of vitamin $\mathrm{D}$ deficiency as a risk factor in autoimmune/inflammatory rheumatic diseases such as RA and now also including IIM. Whether low levels of vitamin $\mathrm{D}$ have a role in the pathogenesis or affect the prognosis is not known and will need further investigation. The results provide guidance for future studies looking at a potential role for vitamin $\mathrm{D}$ in the prevention and/or treatment of IIM.

Acknowledgements The authors thank Eva Jemseby for her assistance with serum samples from the Rheumatology Biobank and nurse Christina Ottosson and Dr Louise Ekholm for their help with administration and data collection.

Contributors PA, IEL: conceived and designed the study, collected and monitored the data, reviewed and analysed the data and wrote the manuscript. SBH: data analysis, statistics, wrote the manuscript and designed the figure. IK, LA and TO: control data collection and analysis, drafting the article. KPA: conceived and designed the study and drafting the article. PC: data collection, drafting the article. All authors gave final approval of the version to be published.

Funding This study was supported by the Swedish Research Council, the AFA Foundation, Knut and Alice Wallenberg's Foundation, the Swedish Council for Working Life and Social Research, the Swedish Rheumatism Association, by the King Gustaf V 80-year Foundation, and through the regional agreement on medical training and clinical research (ALF) between Stockholm County Council and the Karolinska Institutet.

\section{Competing interests None.}

Provenance and peer review Not commissioned; externally peer reviewed.

\section{REFERENCES}

1. Bohan A, Peter JB. Polymyositis and dermatomyositis (first of two parts). N Engl J Med 1975;292:344-7.

2. Griggs RC, Askanas V, DiMauro $\mathrm{S}$, et al. Inclusion body myositis and myopathies. Ann Neurol 1995;38:705-13.

3. Reed $\mathbf{A M}$, Ernste F. The inflammatory milieu in idiopathic inflammatory myositis. Curr Rheumatol Rep 2009;11:295-301.

4. Targoff IN. Idiopathic inflammatory myopathy: autoantibody update. Curr Rheumatol Rep 2002; 4:434-41.

5. Brouwer R, Hengstman GJ, Vree Egberts W, et al. Autoantibody profiles in the sera of European patients with myositis. Ann Rheum Dis 2001:60:116-23.

6. Zampieri S, Ghirardello A, laccarino L, et al. Anti-Jo-1 antibodies. Autoimmunity 2005; 38:73-8

7. Askanas V, Engel WK. Inclusion-body myositis: a myodegenerative conformational disorder associated with Abeta, protein misfolding, and proteasome inhibition. Neurology 2006;66:S39-48

8. Dalakas MC. Sporadic inclusion body myositis_-diagnosis, pathogenesis and therapeutic strategies. Nat Clin Pract Neurol 2006;2:437-47.

9. Reed AM, Ytterberg SR. Genetic and environmental risk factors for idiopathic inflammatory myopathies. Rheum Dis Clin North Am 2002;28:891-16.

10. Atlas E, Novak SN, Duray PH, et al. Lyme myositis: muscle invasion by Borrelia burgdorferi. Ann Intern Med 1988:109:245-6.

11. Okada S, Weatherhead E, Targoff IN, et al. Global surface ultraviolet radiation intensity may modulate the clinical and immunologic expression of autoimmune muscle disease. Arthritis Rheum 2003;48:2285-93.

12. Wortmann RL. Lipid-lowering agents and myopathy. Curr Opin Rheumatol 2002;14:643-7.

13. Hengstman GJ, van Venrooij WJ, Vencovsky J, et al. The relative prevalence of dermatomyositis and polymyositis in Europe exhibits a latitudinal gradient. Ann Rheum Dis 2000;59:141-2.

14. Sontheimer RD. Photoimmunology of lupus erythematosus and dermatomyositis: a speculative review. Photochem Photobiol 1996;63:583-94.

15. Leff RL, Burgess SH, Miller FW, et al. Distinct seasonal patterns in the onset of adult idiopathic inflammatory myopathy in patients with anti-Jo-1 and anti-signal recognition particle autoantibodies. Arthritis Rheum 1991:34:1391-6.

16. Baarnhielm M, Hedstrom AK, Kockum I, et al. Sunlight is associated with decreased multiple sclerosis risk: no interaction with human leukocyte antigen-DRB1*15. Eur J Neurol 2012;19:955-62.

17. Holick MF. Sunlight and vitamin D for bone health and prevention of autoimmune diseases, cancers, and cardiovascular disease. Am J Clin Nutr 2004;80:1678S-88S.

18. Kamen DL, Cooper GS, Bouali $\mathrm{H}$, et al. Vitamin D deficiency in systemic lupus erythematosus. Autoimmun Rev 2006:5:114-17.

19. Cutolo M, Plebani M, Shoenfeld Y, et al. Vitamin D endocrine system and the immune response in rheumatic diseases. Vitam Horm 2011;86:327-51.

20. DeLuca HF. Overview of general physiologic features and functions of vitamin $D$. Am J Clin Nutr 2004:80:1689S-96S.
21. Bhalla AK, Amento EP, Serog B, et al. 1,25-Dihydroxyvitamin D3 inhibits antigen-induced T cell activation. J Immunol 1984;133:1748-54.

22. Lemire JM. Immunomodulatory role of 1,25-dihydroxyvitamin D3. J Cell Biochem 1992; 49:26-31.

23. Mattner F, Smiroldo S, Galbiati F, et al. Inhibition of Th1 development and treatment of chronic-relapsing experimental allergic encephalomyelitis by a non-hypercalcemic analogue of 1,25-dihydroxyvitamin D(3). Eur J Immunol

2000:30:498-508.

24. van Etten E, Mathieu C. Immunoregulation by 1,25-dihydroxyvitamin D3: basic concepts. J Steroid Biochem Mol Biol 2005:97:93-101.

25. Griffin MD, Lutz WH, Phan VA, et al. Potent inhibition of dendritic cell differentiation and maturation by vitamin D analogs. Biochem Biophys Res Commun 2000;270:701-8

26. D'Ambrosio D, Cippitelli M, Cocciolo MG, et al. Inhibition of IL-12 production by 1,25-dihydroxyvitamin D3. Involvement of NF-kappaB downregulation in transcriptional repression of the p40 gene. J Clin Invest 1998;101:252-62.

27. Helming L, Bose J, Ehrchen J, et al. 1alpha,25-Dihydroxyvitamin D3 is a potent suppressor of interferon gamma-mediated macrophage activation. Blood 2005;106:4351-8.

28. Bohan A, Peter JB. Polymyositis and dermatomyositis (second of two parts) N Engl J Med 1975;292:403-7.

29. Hedstrom AK, Sundqvist E, Baarnhielm M, et al. Smoking and two human leukocyte antigen genes interact to increase the risk for multiple sclerosis. Brain 2011;134:653-64.

30. Cantorna MT, Hayes CE, DeLuca HF. 1,25-Dihydroxyvitamin D3 reversibly blocks the progression of relapsing encephalomyelitis, a model of multiple sclerosis. Proc Natl Acad Sci USA 1996;93:7861-4.

31. Sundquist $\mathbf{E}$, Baarnhielm $\mathrm{M}$, Alfredsson $\mathrm{L}$, et al. Confirmation of association between multiple sclerosis and CYP27B1. Eur J Hum Genet 2010;18:1349-52.

32. Deluca HF, Cantorna MT. Vitamin D: its role and uses in immunology. Faseb $J$ 2001;15:2579-85.

33. Burd CJ, Kinyamu HK, Miller FW, et al. UV radiation regulates Mi-2 through protein translation and stability. J Biol Chem 2008;283:34976-82.

34. Birmingham D, Hebert L, Song H, et al. Evidence that abnormally large seasonal declines in vitamin $D$ status may trigger SLE flare in non-African Americans. Lupus 2012;21:855-64.

35. Cutolo M, Otsa K, Laas $\mathrm{K}$, et al. Circannual vitamin d serum levels and disease activity in rheumatoid arthritis: Northern versus Southern Europe. Clin Exp Rheumatol 2006:24:702-4

36. Cutolo M. Rheumatoid arthritis: circadian and circannual rhythms in RA. Nat Rev Rheumatol 2011:7:500-2.

37. Ritterhouse LL, Crowe SR, Niewold TB, et al. Vitamin D deficiency is associated with an increased autoimmune response in healthy individuals and in patients with systemic lupus erythematosus. Ann Rheum Dis 2011;70:1569-74.

38. Mok CC, Birmingham DJ, Ho LY, et al. Vitamin D deficiency as marker for disease activity and damage in systemic lupus erythematosus: a comparison with anti-dsDNA and anti-C1q. Lupus 2012;21:36-42.

39. Eloranta ML, Barbasso Helmers S, Ulfgren AK, et al. A possible mechanism for endogenous activation of the type I interferon system in myositis patients with anti-Jo-1 or anti-Ro 52/anti-Ro 60 autoantibodies. Arthritis Rheum 2007:56:3112-24

40. Krystufkova 0, Vallerskog T, Barbasso Helmers S, et al. Increased serum levels of B cell activating factor (BAFF) in subsets of patients with idiopathic inflammatory myopathies. Ann Rheum Dis 2009;68:836-43.

41. Niewold TB, Kariuki SN, Morgan GA, et al. Elevated serum interferon-alpha activity in juvenile dermatomyositis: associations with disease activity at diagnosis and after thirty-six months of therapy. Arthritis Rheum 2009;60:1815-24.

42. Lindvall B, Bengtsson A, Ernerudh J, et al. Subclinical myositis is common in primary Sjogren's syndrome and is not related to muscle pain. $J$ Rheumato 2002; 29:717-25.

43. Van Etten E, Branisteanu DD, Overbergh $\mathrm{L}$, et al. Combination of a 1,25-dihydroxyvitamin $\mathrm{D} 3$ analog and a bisphosphonate prevents experimental autoimmune encephalomyelitis and preserves bone. Bone 2003:32:397-404.

44. Lemire JM, Archer DC. 1,25-dihydroxyvitamin D3 prevents the in vivo induction of murine experimental autoimmune encephalomyelitis. J Clin Invest 1991;87:1103-7.

45. Cantorna MT, Hayes CE, DeLuca HF. 1,25-Dihydroxycholecalciferol inhibits the progression of arthritis in murine models of human arthritis. J Nutr 1998;128:68-72.

46. Mathieu C, Waer M, Laureys $\mathrm{J}$, et al. Prevention of autoimmune diabetes in NOD mice by 1,25 dihydroxyvitamin D3. Diabetologia 1994;37:552-8.

47. Fournier C, Gepner P, Sadouk M, et al. In vivo beneficial effects of cyclosporin A and 1,25-dihydroxyvitamin D3 on the induction of experimental autoimmune thyroiditis. Clin Immunol Immunopathol 1990;54:53-63.

48. Jagannath VA, Fedorowicz Z, Asokan GV, et al. Vitamin $\mathrm{D}$ for the management of multiple sclerosis. Cochrane Database Syst Rev 2010;CD008422. 